\title{
TOYS AND US: A VISUAL ESSAY ON TOY PHOTOGRAPHY
}

Debora Baldelli

CRIA-ISCTE, Lisbon, Portugal ${ }^{1}$

\begin{abstract}
This photo essay introduces the subject of "Toy Photography", a recent genre in photography, where dolls and action figures "gain life" in staged photos that try to reproduce their environment or story. In "Toy Photography" the intent is to make the toy "lifelike", to remove the "plastic-feel" and make it more "buman". Following Toy Researcher Katrina Heljakka's idea, I believe adults, and not only children, are also interested in reinterpreting and cultivating the meaning of their toy characters by engaging in role-playing and creating new narratives related to their (real or imagined) lives. This photo essay is an autoethnography piece and focuses on reinterpreting the story behind the author and friend's toys in their home environment.
\end{abstract}

Keywords: toy photography, toys, photography, play, autoethnography

Toys are objects for the imagination. They encourage social development. When playing, children are not only creating fantastic scenarios and having an adventure, but they are also simultaneously behaving as themselves and someone else, exploring different perspectives. Yet, toys have also been collectable items for decades. There are communities composed of adults who like to buy toys; some enjoy playing; others take pictures or create videos to post on social media, and most simply keep the toys as part of the home environment. I always loved toys, especially dolls. Recently I realised how many toys I have and I started to wonder why do I like them so much. I also realised how many close friends also have toys in their homes. Is there something behind it or are they just for decoration? In an interconnected world, where social development is sometimes more virtual than real, maybe toys have also use for adults in helping them understand the world they live in. Maybe toys help some adults keep perhaps a visual reference of something they relate to as a person; something that tells them who they are or who they wanted to be.

1 Member of the Centre for Research in Anthropology (CRIA). Contact: imaginarydebora@gmail.com | www. imaginarydebora.com. I would to thank Ines David for proofreading the first version of this article; and Lucy Blue for proofreading its final version. 
Please find the complete photo gallery here:

https://journals.openedition.org/cadernosaa/1467

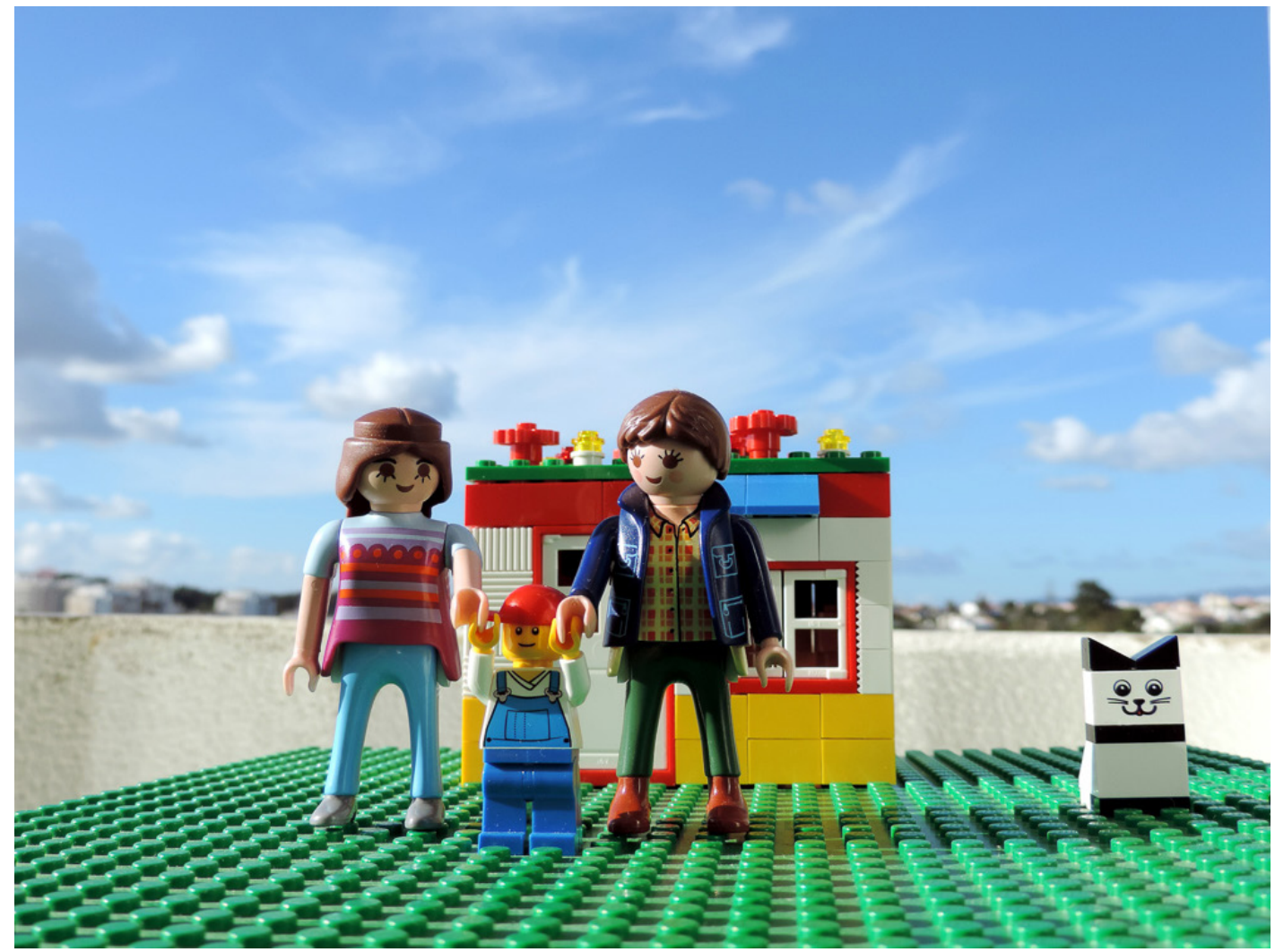

“Toy Researcher" Katriina Heljakka (2016) proposes to discuss why the manipulation of toys in adult age is considered hobbying and not playing and why many think that play only belongs in childhood. While children are expected to immerse themselves in play, adults can allegedly maintain a connection to play by preserving a playful attitude (pg. 5). Attfield (1996) suggests instead of seeing toys from the perspective of commodities one should observe how they, in use, are transformed into material culture. To Heljakka,

play with character toys is fundamentally an imaginative and therefore creative activity which uses backstories as inspiration but does not necessarily limit itself to them. On the contrary, players of all ages constantly demonstrate their ability to challenge (and even subvert) suggested backstories. Toys could be viewed as portals to imagination that serve players of different ages and that carry in them the potential to trigger rich forms of storytelling (imagined worlds and characters or paracosms) in the hands (or the minds) of the players (2016:7).

In the article entitled "Getting started in Toy Photography", Mom Macutay, in a section called "The Art of Toy Photography" says the challenge of Toy Photography is to make the toy "lifelike", to remove the "plastic-feel" and make it more "human". Considering each toy has an "origin" and a story behind it you should try to create thematic scenarios by interacting with everyday objects. This interaction, instead of being a "solitary object play practice", becomes a social one transcending from the domestic sphere into the realm of the public playscape when shared on social media platforms such as Instagram, Flickr or Facebook. For example, the stuffed "monkey girl" called @loris_the_monkey on Instagram has 1,605 people following her trips to Europe and beyond. She also has a Facebook profile. Loris is an example of people replacing themselves in pictures and recreating themselves as a character. This is considered "photoplay" (Heljakka, 2016). Following specialist Katrina Heljakka's idea, I believe adults, 
and not only children, are also interested in reinterpreting and cultivating the meaning of their toy characters by engaging in role-playing and creating new narratives related to their (real or imagined) lives, and are further interested in how toys can function as instruments of imagination and "autotelic play" (2016:12;15). In this photo essay, I try to put these ideas in action by creating photos of toys that also talk about myself.

This photo essay focuses on portraits of my toys and of some friends. It is an effort to explore new ways of telling stories by using photography and autoethnography as creative tools for investigation and artistic expression.

I understand Autoethnography as an autobiographical genre of writing and research connecting the personal to the cultural and presented in a variety of forms: short stories, poetry, fiction, novels, photographic essays and social science prose (Ellis \& Bochner 2000:739). Carolyn Ellis, an anthropologist specialized in Autoethnography, says one of the efforts of the genre is to make social science less anonymous and more personal, also privileging stories over analysis. The author proposes the following question: why should we be ashamed of our work if it has therapeutic or personal value? (Ellis \& Bochner 2000:746) For Alec Grant and Laetitia Zeeman, "researchers, including autoethnographers are well placed to write about their reflexive biographical engagement with culture, since they are, by definition, experts by experience", emphasizing as well that "we all live storied lives and our stories are relational, embodied and performative”. (2012:2).

In the case of Photography, it can be a starting point or a result, or both (Guran, 2000). Photography can be exploratory and also very revealing of aspects not focused on the moment the pictures were taken. One of its potentialities is to highlight a particular aspect of reality that is diluted in a vast field of vision, thus explaining the uniqueness of a scene (ibid. p.157).

According to anthropologist and photographer Milton Guran, the major contribution of photography to research and anthropological discourse lies in the fact that it forces a perception of the world different from that required by other research methods, thus giving access to information that would hardly be obtained by others means (2000: 158).

I got interested in making pictures of toys during my $\mathrm{PhD}$, as something to take my mind off my thesis. I bought a few Legos to play and, realising I liked toys, a few friends started to give me toy-related gifts. This later grew to become the subject of my capstone project during a specialisation in Photography in 2017, which I started after finishing writing my thesis.

My initial idea was to create a photographic project focusing on portraits, but I had just moved to a new city and I did not know many people, so I started playing with toys to try to create scenarios that could tell a story or recreate a memory. After the long tense period of the process of writing a thesis, all I wanted was to play, to explore new ways of being creative. It was a time for reflection, for not being tied up to deadlines, to figure out a way to be myself again. I felt like my spirit was crushed from the $\mathrm{PhD}$ for being obligated to write what I needed to be able to finish in time, to write to please my advisor, colleague's expectations and academic standards.

For creative people that enjoy writing, a PhD thesis can be just the opposite of what they expected, a big mistake, just like the ones made by people who like kids and decide to be pae- 
diatricians to end seeing them sick and dying all the time. I was in a constant "language battle" between my writing in Portuguese from Brazil and the academic writing standards of Portugal, which I did not like. My writing style, which was always "too creative" for academic standards, were seen as inappropriate (or just bad writing) to my advisor standards. So, I believe it is not a surprise that after I finished the $\mathrm{PhD}$, I started looking for other ways of expressing myself, to look for new artistic languages. From the moment I ended my PhD, up until now, photography and Autoethnography (or non-fiction creative writing) has been my method of finding my way back to being creative and to look for other academic paths.

To me Toy Photography was certainly a game, a product of chance, a way to express myself and to live the moment I was going through. Photography has a unique relationship to chance, a mixed blessing for who wants to make photographic art (Kelsey, 2015). To photography professor Robin Kelsey (2015), photography has also an extraordinary capacity to represent the unpredictable dynamism of modern life. I took every opportunity I had to create toy photography scenarios no matter where I was. Although these pictures don't tell a story in sequence, they all reflect moments from my daily life, dialogues I created with friends and family depending on where I was, and also (why not?), my hopes and desires.

The pictures were taken in three different cities, Portimão, Lisbon and Cambridge, in homes of friends and family. My intention was always to create something not just fun, but funny, even by recreating a well-known scenario of a movie or by adjusting real scenarios to the possibilities of a home. For example, the sink would become the sea for the "male mermaid". Most of these pictures also say a lot about myself and about the moment I was going through when they were taken.

The first set of pictures (from 1 to 7), shows staged photos of well-known characters focusing on some aspect of their own story, but using the home environment as the set. Sarah (photo 1 and 2), from the movie Labyrinth, is in a scary labyrinth of bananas that is full of shades in the first photo. In the second one, she is out of the record player, meaning she was able to free herself from the idea of walking in circles related to labyrinths. Sarah was given to me during a trip to Cambridge, where the pictures were taken. Sarah is "me" in a way. The labyrinth is the place I felt when those pictures were taken after finishing a $\mathrm{PhD}$ and trying to figure out the next step.

Alf (photos 3 and 4), from the TV series of the same name, is an alien who crashes his spaceship in a suburban garage. He is known for having a bad attitude. In the first picture, he is feeling bored and in the second he is being punished by his owner for his bad behaviour. The story behind Alf is the out of place feeling felt by immigrants. Alf's owner and myself constantly talk about how we feel and the challenges of living in a different country, which I believe are ironically portrayed by these two pictures.

Eleven (photos 5 and 6), the character of Stranger Things is on one of the iconic sets of the TV series: a sofa with lights above and she is being attacked by a "Demogorgon" in the shape of a cat in the second photo. ${ }^{2}$ This picture was created at one of my closest friend's home with her daughter, the owner of the doll. I proposed creating the scenario as a game for us to try to recreate some of the series' scenes. This friend and her daughter were constantly giving 
me emotional support during the last phase of my $\mathrm{PhD}$ writing just by being a great enjoyable company, taking my mind of the thesis.

ET (photo 7) is close to the telephone in the setting of one of his favourite lines: "ET phone home". This picture also follows the same feeling as Sarah's labyrinth. Photo 8 shows what I called a "male hipster mermaid", but it could also be seen as the Triton, from Greek mythology. He is in the perfect setting for a being that needs to be close to the water, which is something I can relate to. It is also a reflection of where I lived at the time, just two blocks from a beach.

Pictures 9 and 10 are called "new families". They were inspired by a photo I created for the project Consenses Monthly challenge (Dec. 2017) called "being parents", ${ }^{3}$ which shows a composition of a family of two women, a son and a cat in "their" home environment. This picture was initially created as part of a game proposed by Consenses whereby you interpret something (e.g. a song, a poem, a painting or a picture). I made an interpretation of a painting of two women with a strong look, which made me want to create a picture of an LGBT family. This family was composed of two women and a son. The inspiration came from one of my closest friends, who recently had a boy with her partner.

The last picture (11), which I call "the smurf anthropologist" showcases a smurf and a book about gnomes. This is probably the most personal photo of this essay. The book about gnomes is the only one I have left from my childhood and is also my favourite book from that time. Ultimately, it is an imaginary/fantasy study about the habits and behaviour of a particular population, which signals my interests in studying human behaviour since childhood. I composed this picture as a self-portrait.

\section{REFERENCES:}

Attfield, 1996, "Barbie and action man: Adult toys for the girls and boys, 1959-93; In: P. Kirkham (ed.), The gendered object, Manchester University Press, pp. 80-89.

Ellis, Carolyn \& Bochner, Arthur P., 2000, "Autoethnography, personal narrative, reflexivity: Research as subject; In: N.K. Denzin \& Y.S. Lincoln (Eds.), Handbook of qualitative research, Second Edition; pp.733-768.

Grant, Alec \& Zeeman, Laetitia, 2012, "Whose Story Is It? An Autoethnography Concerning Narrative Identity”; In: The Qualitative Report, Volume 17, Number 36; TQR; pp.1-12. Guran, Milton, 2000, "Fotografar para descobrir, fotografar para contar"; In: Cadernos de Antropologia e Imagem, 10(1), pp.155-165.

Heljakka, Katrina Irja, 2016, "More than Collectors: Exploring Theorists'Hobbyists' and Everyday Players' Rhetoric in Adult Play with Characer Toys"; In: Games and Culture, Sage Publications, pp.1-20.

Kelsey, Robin, 2015, Photography and the Art of Chance, Belknap Press.

3 For more information, please visit http://consenses.org/. 
Macutay, Mon, "Getting started in Toy Photography", no date. https://digital-photographyschool.com/getting-started-in-toy-photography/ (acessed on 23/02/18).

Date received: 2018-02-23

Date accepted: 2018-08-08 